\title{
Laser Scanning Technology for Bridge Monitoring
}

\author{
Shen-En Chen \\ Department of Civil and Environmental Engineering \\ University of North Carolina at Charlotte
}

USA

\section{Introduction}

After the collapse of the Minnesota I-35 bridge (August 1, 2007), there has been a renewed interest in the US to enhance bridge infrastructure monitoring (Liu et al., 2009). Other than developing traditional inspection and material testing techniques, there has been also increased discussions about possible applications of Commercial Remote Sensing (CRS) technologies for civil infrastructure monitoring (Al-Turk \& Uddin, 1999, Shinozuka \& Rejajaie, 2000, Chen et al., 2011). Laser scanning techniques are one of the remote sensing technologies that play significant role in environmental and infrastructure evaluation and monitoring. However, there are different sensing requirements for monitoring physical structures such as bridges, than conventional geospatial applications such as air quality, environmental impact and transportation operations, etc. The most important of which is the sensor resolution requirement.

This chapter discusses critical bridge monitoring issues and provides examples of applications of two laser scanner technologies that are currently being developed for bridge monitoring: 1) range finding laser (static) and 2) scanning laser vibrometer (dynamic). Both laser systems are terrestrial and single point systems that utilize mechanical or optical scanning mechanisms to create a field of view (FOV) of the optical receiver.

The range finding laser, also called LiDAR (for Light Detection and Ranging), is based on the transmission and receiving of pulsed lights. By determining the heterodyne laser beam phase shifts, scanning LiDAR can detect the distance information from a plane of data points, called point cloud. The point cloud information, which basically consists of the physical positions of any surface that the laser "sees", can then be used to detect useful critical information about a structure including the elevation (underclearance), surface (damage quantification) and deformation under loading (deflection), etc. Contrast to conventional analysis of photographic images, relatively simple algorithms can be used to manipulate the geometric point cloud data to retrieve the afore-mentioned information. Other bridge-related issues including validation of new constructions and comparisons before- and after critical event, can also be extracted from LiDAR scans. 
Based on the measurement of Doppler effects of a returning continuous laser beam from a moving target, the scanning laser vibrometer (SLV) is a laser system that can detect the vibration of a subject. By covering the entire surface of a subject, SLV can not only detect the vibration frequencies but is able to separate the different vibration mode shapes of the subject (Oliver, 1995). This makes the SLV a very useful tool in isolating vibration-induced problems and in some cases, detect system or component level damages.

Because of the non-contact nature and the ability of sensing from a distance away, scanning lasers have the advantages of limited disruption to traffic, low labor requirements and providing permanent electronic documentations of the temporal changes of a structure. Scanning Laser is ideal as a bridge field inspection tool and can help reduce the costs of inspection and at the same time, enhance the accuracy in field inspections.

However, to implement laser scanning systems into bridge evaluation, one needs to understand the basics of bridge inspection practices and issues, in particular, recognizes the fact that some bridge issues are not necessarily associated with condition assessment, but with serviceability requirements such as adequate bridge underclearance, excessive bridge movements or traffic-induced vibrations.

Scanning lasers alone will not provide the critical information associated with bridge inspection, additional evaluation methodologies usually are needed to extract the necessary information associated with the bridge problems. The examples provided will demonstrate some additional physical theories that can be used to identify critical bridge information that affiliate with actual structural conditions.

\section{Scanning laser technologies}

The scanning laser technologies described herein can be best described as mid-range, terrestrial (ground-based) laser scanning systems that have found significant bridge health monitoring applications. The 3D scanning laser or LiDAR is a static laser that is a close cousin of the airborne LiDAR systems that generates large landscape footprints (Rueger, 1990). The SLV is the 2D dynamic laser systems that measures motions of specific position points based on Doppler shift measurements (Drain, 1980). Figure 1 shows the basic system components for both systems which include the ranging unit, the scanning mechanism, the laser controller and the data recorder.

Most laser scanners use servo-controlled rotating mirrors to reflect the laser beams on the target surface and usually allow the coverage of two-dimensional or three-dimensional areas. The servo-controller or galvanometers can be either moving-iron or moving-coil types and can be multiple-axial systems. The movable mirror system can be either through the use of a hexagonal mirror or the use of multiple-axis rotating flat mirrors. Laser beams bounce off the mirror and travel to different positions on the target and returns to the same mirror system. The returned laser beam help create the position data from the target surface. Most servo-controlled, rotating mirror has a fixed scanning speed. Hence, depending on the demand of data points, the duration of scan can vary from few minutes to several minutes. Figure 2 shows an example of a schematic moving-iron type galvanometer. 


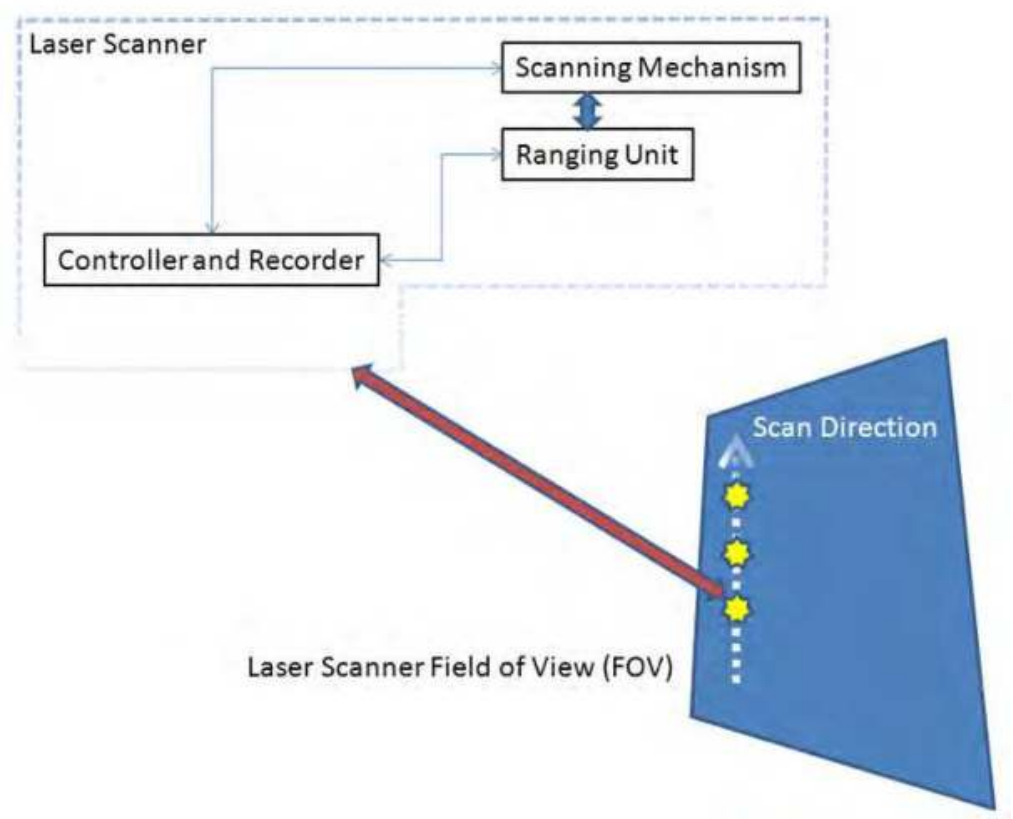

Fig. 1. Terrestrial Laser Scanning System Components

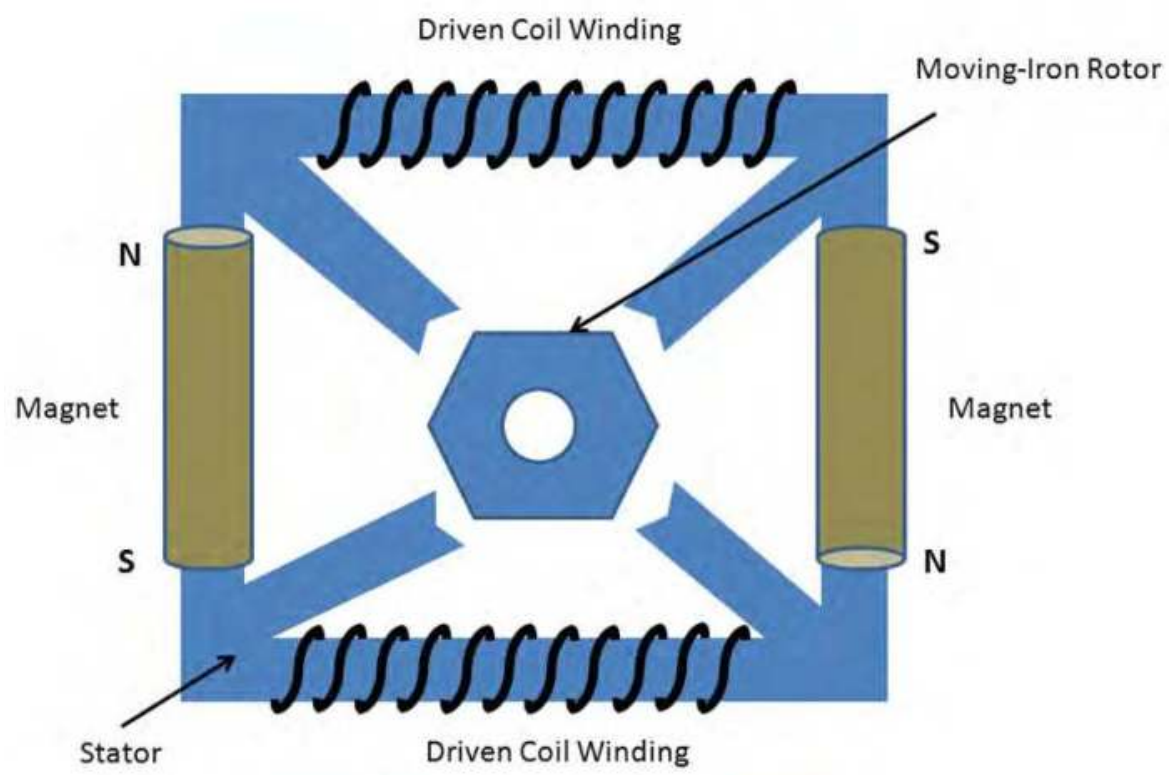

Fig. 2. Moving-Iron Galvanometer 


\subsection{D scanning LiDAR}

Figure 3 shows a scanning LiDAR and basics of the detection of returning signals. There are two approaches to the detection of the position data: 1) time of flight differences between emitted pulse and returned signals and 2) phase differences between the two signals (Jelalian, 1992). In a typical five to ten minute scan, the scanning LiDAR unit can collect millions of data points that include the XYZ position of each scan point. Applications of LiDAR scans are multi-facet: Airborne, long range LiDARs have been used in terrain mapping, ground canopy detection and environmental impact studies. Smith et al. (1997) reported using a Lawrence Livermore National Laboratory (LLNL) LiDAR for lunar surface (topography) measurements from the Clementine spacecraft. The solid state Nd:TAG (wavelength of $1.064 \mathrm{~mm}$ ) laser has a maximum target range of $640 \mathrm{~km}$.

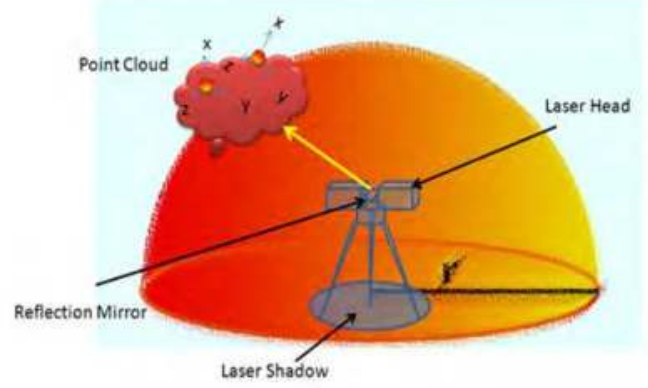

a) 3D LIDAR and FOV

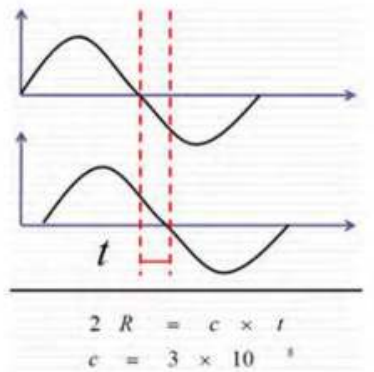

b) Range Determination

Fig. 3. Optical Principles of LiDAR: a) 3D LiDAR and Idealized Field of View (FOV); b) Basic Range Detection from Laser Wave Signals.

Scanning laser technology for structural monitoring really took off since the 1990s (Fritsch \& Kilian, 1994): For infrastructure monitoring applications, Al-Turk and Uddin (1999) reported using airborne LiDAR for terrain and roadway mapping with the intent of assessing infrastructure inventory; for structural geometric measurements, Curless and Levoy (1996) reported using laser range finder to construct 3D structural geometry of historical structures; subsequently, several reports described using scanning LiDAR for detection of structural changes (Lichti \& Gordon, 2004, Girardeau-Montaut \& Roux, 2005, Pieraccini \& Parrini, 2007).

For bridge applications, Lefevre (2000) first reported using radar for measuring bridge clearances. By comparing the position change of the scan points at each measurement location, deflection of bridge component can be measured. Fuchs et al. (2004a and 2004b) reported using LiDAR for displacement measurements during several bridge static load tests. However, to monitor multiple lines of a bridge during a load test, their laser needed to be placed at multiple locations manually. The accuracy of this measurement method was indicated to be at $\pm 0.76 \mathrm{~mm}$. There have also been reports of using vehicle-mounted scanning systems for bridge clearance measurements: when traveling at traffic speed, this technique can significantly reduce the time for bridge inspection (Kim et al., 2008). Liu et al. (2010a, 2010b and 2011) described several applications of scanning laser system for bridge monitoring applications. 
On a tripod, the 3D scanning laser can be imagined to scatter the laser beams covering a sphere around the scanner (Figure 3). Depending on the design, there may be a "blind spot" where the laser will not be able to "see" (the laser shadow). Application of 3D LiDAR to image monitoring relies on the placement of the bridge to within the FOV and the construction of a dense point cloud image of the bridge or bridge components. Since terrestrial LiDAR scans from a single position, depending on the application, there may be the need to move the LiDAR to different physical positions in order to establish a complete image. Table 1 summarizes the different LiDAR applications for bridge monitoring and also the resolution requirements associated with each application.

Essential to LiDAR point cloud analysis is the appreciation of the geometric complexities of the scanned scene and how it ties to the position differences for the subject-of-interest. The position differences can be the calculation of the physical distances for subjects within the same scan or the differences between different scans (deformations) of the same subject. Before a bridge scan, the scanner should be calibrated such that each scan point represents the relative point position $(X, Y, Z)$ to the scanner. Two approaches to the valuation of the scanned XYZ data are presented: 1) the Distance and Gradient Criterion (DGC) based method (Liu et al., 2010a) and 2) the Mean Sum Error and Triangulation (MSE\&T) based method (Bian et al. 2011).

\begin{tabular}{|l|l|l|}
\hline Applications & $\begin{array}{l}\text { Geometric } \\
\text { Dimensions }\end{array}$ & $\begin{array}{l}\text { Resolution Requirements (not } \\
\text { verified) }\end{array}$ \\
\hline Bridge damage detection & $\mathrm{L}^{2}, \mathrm{~L}^{3}$ & $\pm 0.0001 \mathrm{~m}^{2}, \pm 0.000001 \mathrm{~m}^{3}$ \\
\hline Clearance measurements & $\mathrm{L}$ & $\pm 0.001 \mathrm{~m}$ \\
\hline Bridge displacement & $\mathrm{L}$ & $\pm 0.001 \mathrm{~m}$ \\
\hline Accident study & $\mathrm{L}, \mathrm{L}^{2}, \mathrm{~L}^{3}$ & $\pm 0.1 \mathrm{~m}, \pm 0.01 \mathrm{~m}^{2}, \pm 0.001 \mathrm{~m}^{3}$ \\
\hline Pre- and Post-construction/event & $\mathrm{L}, \mathrm{L}^{2}, \mathrm{~L}^{3}$ & $\pm 0.1 \mathrm{~m}, \pm 0.01 \mathrm{~m}^{2}, \pm 0.001 \mathrm{~m}^{3}$ \\
\hline Traffic loading quantification & $\mathrm{L}, \mathrm{L} / \mathrm{T}$ & $\pm 0.1 \mathrm{~m}, \pm 0.01 \mathrm{~m}^{2}, \pm 0.001 \mathrm{~m}^{3}$ \\
\hline Temperature effect & $\mathrm{L}$ & $\pm 0.1 \mathrm{~m}, \pm 0.01 \mathrm{~m}^{2}, \pm 0.001 \mathrm{~m}^{3}$ \\
\hline Furniture detection & $\mathrm{L}^{2}$ & $\pm 0.01 \mathrm{~m}^{2}$ \\
\hline Abuse (graffiti, homeless) detection & $\mathrm{L}^{2}$ & $\pm 0.01 \mathrm{~m}^{2}$ \\
\hline
\end{tabular}

Table 1. Potential LiDAR Applications

The DGC method depends on a two-criterion qualifier that defines different portions of the recorded point cloud. A reference plane for the selected point cloud is first defined, which is used to compare with the recorded data to identify the actual area of interest. The validity of each point within the area is then checked by comparing their coordinate value to the surrounding scan points using a search algorithm. For damage detection on a surface, irregular scan points of the selected area are identified by comparing the coordinate differentials between any neighbouring points and comparing the changes in gradient value of the scan points. These two criteria help to determine whether a scan point belongs to the defective part/parts.

Since the selected study area has been rotated and is parallel to the $\mathrm{XY}$ plane, D, the distance between the scan points to the reference plane can be easily obtained as

$$
D=\left|Z_{P}-Z_{R E F}\right|
$$


where $Z_{P}$ is the $Z$ coordinate values of the selected points, and $Z_{R E F}$ is the $Z$ coordinate value of the reference plane. The gradient of a certain irregular scan point, which has a column number $\mathrm{C}$ and row number $\mathrm{R}$, can be represented as:

$$
\begin{aligned}
& G=\left|\frac{Z(C+\Delta, R)-Z(C-\Delta, R)}{\sqrt{(X(C+\Delta, R)-X(C-\Delta, R))^{2}+(Y(C+\Delta, R)-Y(C-\Delta, R))^{2}}}\right|, \\
& +\left|\frac{Z(C, R+\Delta)-Z(C, R-\Delta)}{\sqrt{(X(C, R+\Delta)-X(C, R-\Delta))^{2}+(Y(C, R+\Delta)-Y(C, R-\Delta))^{2}}}\right|
\end{aligned}
$$

where $X(C, R), Y(C, R), Z(C, R)$ is the $X, Y, Z$ coordinate values of the selected point with a column number $C$ and row number R. $\Delta$ is the number of points in each pre-established interval.

In the second method, Mean Sum Error (MSE) and the Delaunay triangulation calculations are used: two-variable regression is used to find an optimal reference plane with the least MSE. Linear reference plane for the selected area can be any surface that contains no anomalies. The MSE regression of each point is calculated against the reference surface and is defined as:

$$
M S E=\frac{\sum_{i=1}^{n}\left(d_{i}\right)^{2}}{n}
$$

where $\mathrm{n}$ is the number of the selected cloud points, and $\mathrm{d}_{i}$ is the distance of point $i$ to the reference plane $(i=1, \ldots, \mathrm{n}$, respectively):

$$
d_{i}=\left|\varepsilon_{i}\right|
$$

where $\varepsilon_{i}$ is the error, which is the identified distance to the reference plane.

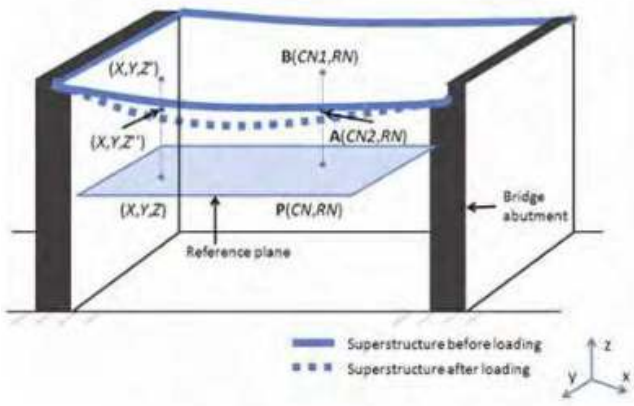

a) DGC Method

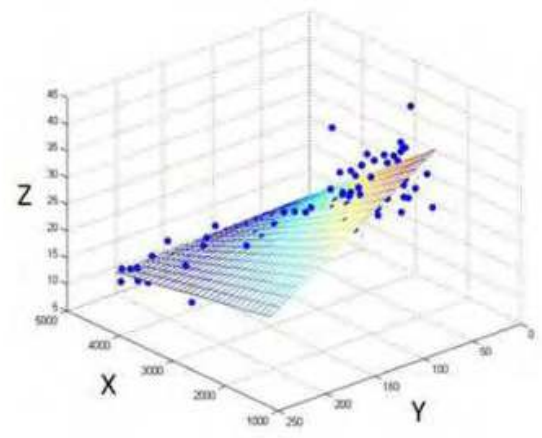

b) MSE\&T Method

Fig. 4. Conceptual Differences between DGC and MSE\&T Methods (Bian et al., 2011) 
MSE\&T method uses the distance from scan points to the reference plane as the criterion to identify the defective parts. Therefore, a pre-determined tolerance value needs to be manually assigned before detecting the defective areas. After that, the Delaunay's triangulation algorithm is used to aggregate the projected points on $X-Y$ plane and the $z$ value is then assigned back to the projected point set, thus forming a 3D surface. Figure 4 shows the conceptual differences between the two methods: a) DGC and b) MSE\&T.

Boehler and Marbs (2002) investigated the accuracies of 3D scanning technologies and identified several factors that can influence the scanner accuracies including temperature, atmospheric (lighting) and interfering radiations. The scanning angles between the laser and the target can result in significant scattering of the laser energy and reduce angular accuracy of the laser.

\subsection{Scanning laser vibrometry}

Laser Doppler vibrometer (LDV) functions by emitting a continuous laser beam to the target surface and measure the vibration of the surface using the Doppler shift between the incident beam and the returned beam (Drain 1980). Figure 5 shows one of the simpler arrangements of a LDV sensor, showing the laser beam being split into a target beam and a reference beam. The two beams are then coupled at the detector. If the laser has a wave length, $\lambda$, and the target is moving at a velocity, $v$, then the moving velocity can be determined by computing the frequency shift between the reference and the target beam:

$$
v=\frac{f \lambda}{2}
$$

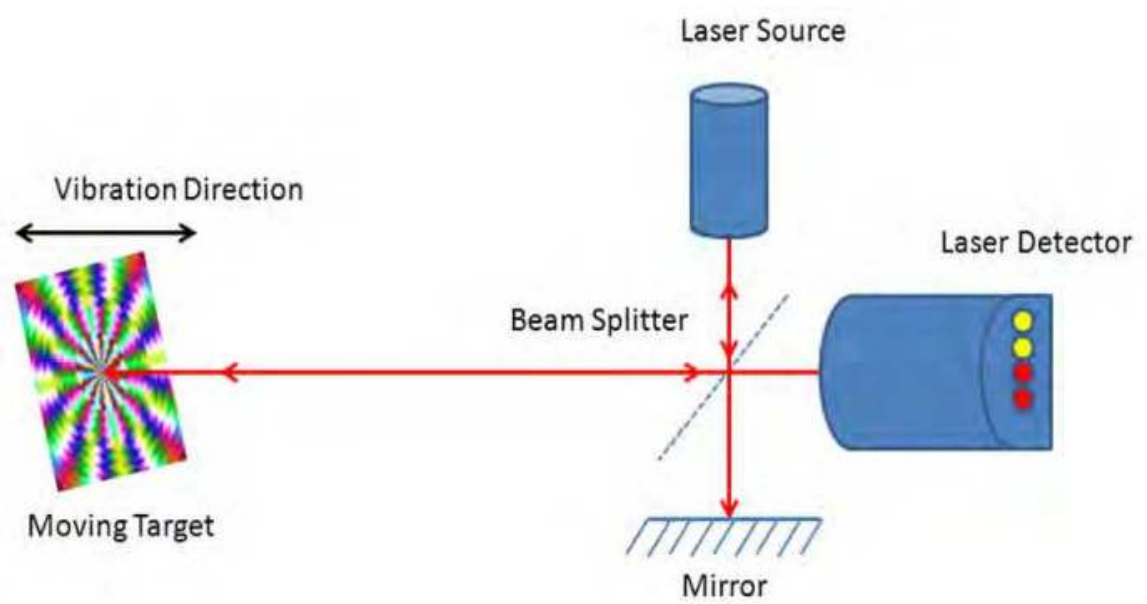

Fig. 5. LDV Sensor Principle

Two optical systems are commercially available: 1) Bragg Cell modulators and 2) Michelson interferometry. One of the key features of the SLV is that it potentially has no data density limitation and the sensitivity of the sensor improves as spatial data density is increased. Contrast to contact sensors, such as accelerometers, there is a limit to how many spatial 
points can be practically measured. SLV has been used extensively in the automobile industry for studying dynamic behaviors of cars (Junge, 1994). Other advantages of using a SLV for inspection include:

- no added mass on the structure,

- full-field measurement capability,

- speed test setup,

- accurate measurements,

- $\quad$ central remote operation (Oliver, 1995)

\section{Examples of LiDAR applications for bridge monitoring}

\subsection{D LiDAR for bridge damage evaluation}

Surface damages in concrete members are common as a result of either excessive loading or environmentally-induced internal stressing (such as erosion or corrosion of rebars). Early detection of these surficial damages can enhance the durability and the preservation of the structures. Figure 6 shows typical damages to bridge concrete girders in the form of mass losses. The scanned image consists of three girders with girders 2 and 3 showing significant mass losses. If the mass loss can be repaired in time, corrosion resulting from the exposed rebars can be prevented. Using LiDAR scans, four defective areas were identified on two of the four scanned girders and the mass loss areas and volumes for each defective area are quantified (Liu et al. 2010a).

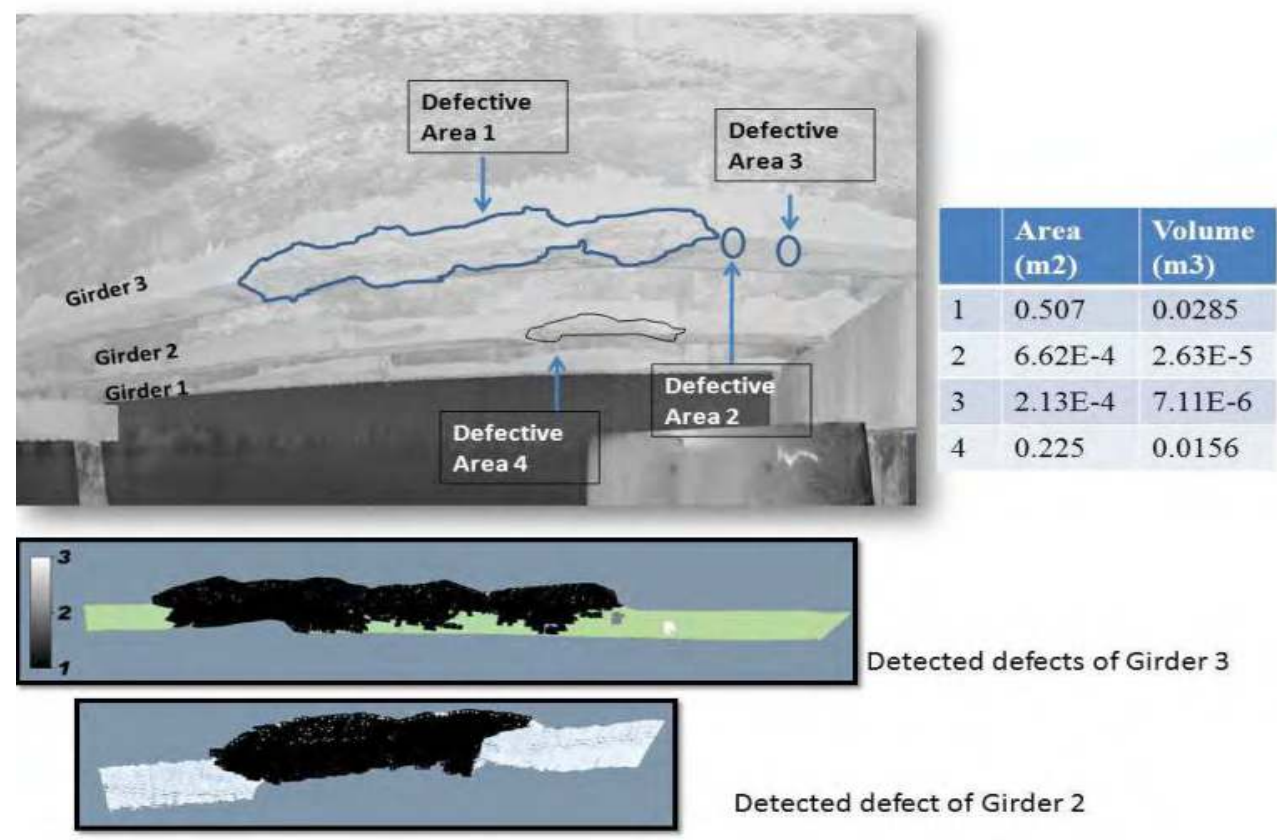

Fig. 6. Damage (Mass Loss) Quantification on Concrete Bridge Girders Using 3D LiDAR (Liu et al., 2010a) 
Such damages can also occur when a bridge does not have the required clearances and resulted in vehicle collisions to the bridge superstructures. Hence, the underclearance measurements for a bridge are very important.

\subsection{D LiDAR for bridge underclearance measurements}

Conventional clearance measurements are performed using surveying equipment and usually several measurement points are needed to determine the lowest point underneath a bridge, which is a time consuming process. LiDAR systems can provide bridge vertical clearance information for the entire bridge with accuracies in the order of millimeters. The display of clearance change over the entire bridge coverage area can be useful to assess damages and help engineers to devise bridge improvement planning. Using truck-mount LiDAR system, it is even possible to determine bridge clearance on the fly without stopping ongoing traffics (Kim et al., 2008).

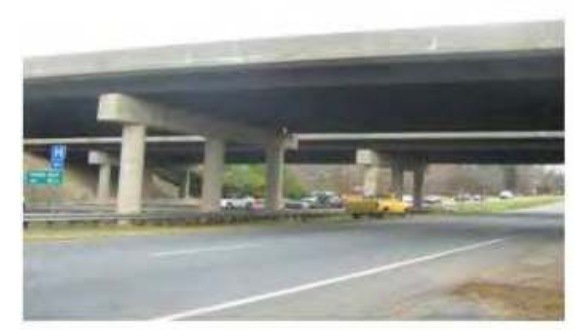

a) Harris Boulevard Bridge

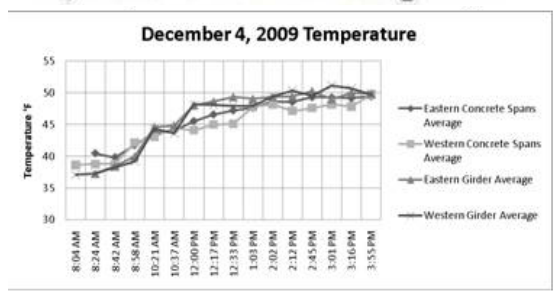

c) Temperature Deviation (Winter Scan)

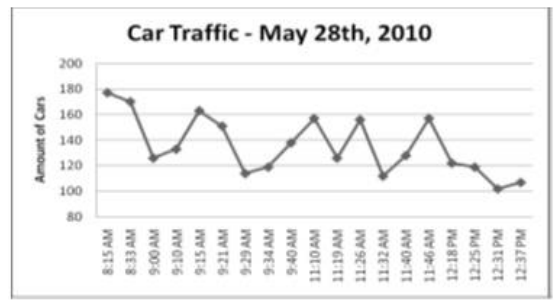

e) Traffic Data (Winter Scan)

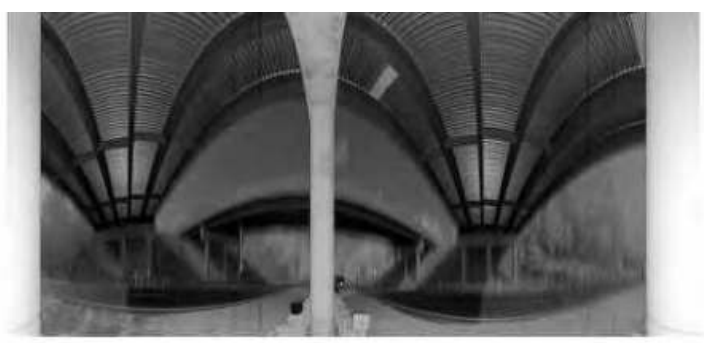

b) Laser Scan of Both Spans

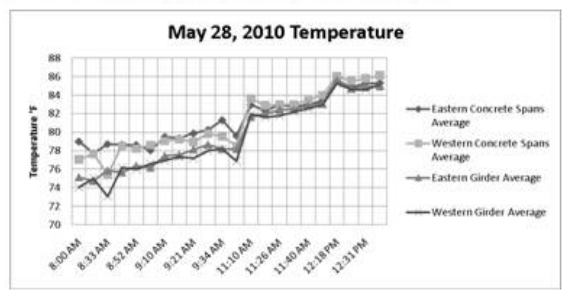

d) Temperature Deviation (Spring Scan)

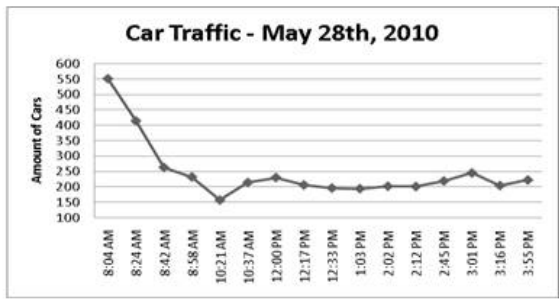

f) Traffic Data (Spring Scan)

Fig. 7. Laser Scan of Harris Boulevard Bridge: a) Harris Boulevard Bridge; b) Laser Scan Showing Both Spans; c) Temperature Deviation during Winter Scan; d) Temperature Deviation During Spring Scan; e) Winter Scan Traffic; and f) Spring Scan Traffic. (Watson et al., 2011) 
However, it is necessary to establish the effects of traffic loading over the bridge to ensure no large displacements occur due to vehicle crossing. A temperature and traffic effects study is conducted on the Harris Boulevard Bridge, Charlotte, NC (Watson et al. 2011). Multiple scans were conducted during a day in the winter of 2009 and a day in the late spring of 2010. Figure 7 shows a) the bridge, b) example laser scan, c) winter temperature deviation, d) spring temperature deviation, e) winter traffic and f) spring traffic. Statistical analysis and a hypothesis testing were conducted on the test results to determine if the measurement deviations can be tied to either temperature effects or the passing traffics on the bridge. The statistical analysis and hypothesis testing indicated that LiDAR scans were not influenced by the weather or traffic effects.

\subsection{D LiDAR for post blast assessment}

The Colony Road Bridge is a concrete culvert with a two-lane road above. The abutments of the culvert are backfilled with earth, which is retained by large trees, shrubs, and large granite gravel to protect the embankments and foundation culvert from erosion. At both openings of the culvert are wing walls that angled out from the culvert. The culvert crosses the Briars Creek which is about ten meters wide. Figure 8 outlines the basic geometry of the culvert, which has a width of $10.4 \mathrm{~m}$ and a height of $5.7 \mathrm{~m}$.

For the Colony Road Bridge, there were several concerns with respect to a construction blasting project: A layer of rock had to be removed in order to lay a new sanitary pipe, but the construction area is nearby to the reinforced concrete culvert, a school, and family homes. The structure of most concern was the concrete culvert as the blasting would occur only 11 meters away from the structure, which is less than the allowable distance of a blasting from the City Ordinance (Charlotte City Council, 2011).

The blast plan called for $3.67 \mathrm{~kg}$ of high explosives including: 2x16 dynamite and 21/2x16 unimax blasting agent. The drill pattern was $1.54 \times 1.83$ with 20 to 30 holes drilled. The diameters of bore holes were approximately $0.089 \mathrm{~m}$ with a depth of 0.762 . The blasting was done to remove a 3.96 layer of rock below 5.18 of earth so that a new 1.52 diameter sanitary sewer could be constructed. Figure 8(a) shows the location of the blast site and the location of the concrete culvert. Also shown are the blast records indicating blast less than $50 \mathrm{~mm} / \mathrm{sec}$ limit.

The geophones placed on the Colony Road bridge detected vibrations up to $37.08 \mathrm{~mm} / \mathrm{sec}$. As a follow up to assessing the structure, a laser scan and post blasting analysis of the culvert were performed to determine if any noticeable permanent damage could be detected using terrestrial LiDAR. A set of LiDAR scans from before blasting was taken and compared to a set of scans after the blasting event. Figure 8(b) contains a black and white rendering top image of the reflectivity image of the Colony Road Bridge after the blasting. As shown the plants around the bridge have since grown to much higher and obscured much of the bridge. Figure 8(c) shows a comparison of the two scans indicating a difference value. Although small areas of the comparison result may show positive or negative displacements, this is expected as individual points may fall outside of the expected accuracy deviation. However, there is no general trend in the data to suggest that the structure has been moved or has been damaged by the blasting. 


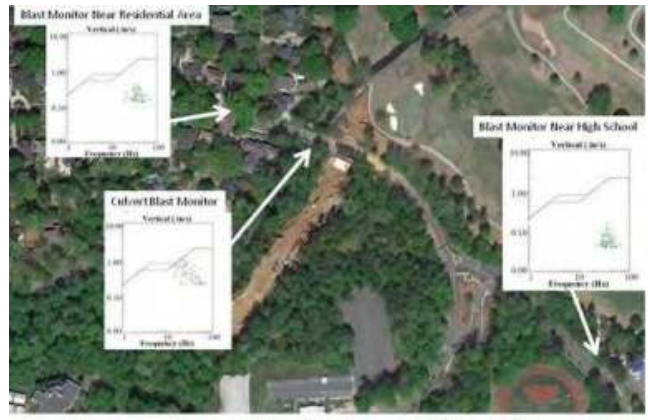

a) Colony Road Blast Site and Blast Records

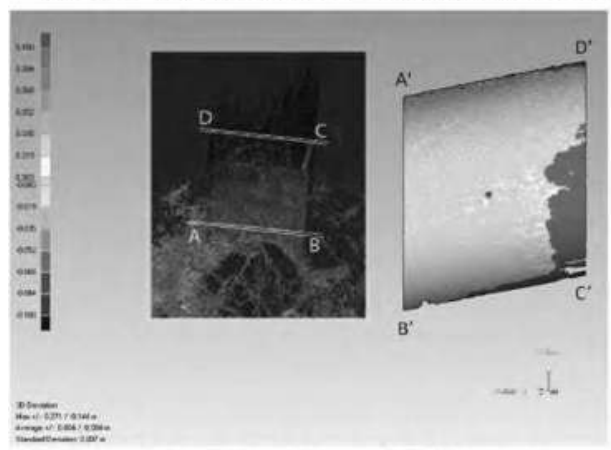

c) Pre and Post Blast Geometric Comparisons

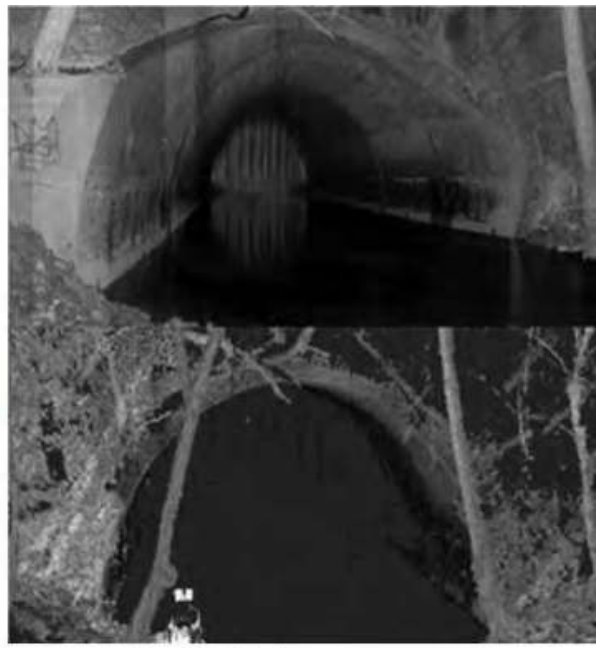

b) LiDAR Scan

Fig. 8. Colony Road Blasting: a) Colony Road Bridge Location; b) LiDAR Scan; c) Position Before and After Blasting Compared

\subsection{Scanning laser for bridge deflection measurements}

Load testing of bridges has been well recognized as a practical method to study the condition of bridges. Abnormal behavior of a bridge under a load test is a sign for the need for more frequent inspections and maintenance works. Bridge under given static load is often measured for displacement, stress, or strain of selected points using contact sensors such as strain gauges and displacement transducers. A skewed hybrid high performance steel (HPS) bridge located on SR1102 (Langtree Road) over I-77 in Iredell County, NC, have been studied using LiDAR scans and truck loading (Figure 9(a)). The bridge consists of two $46 \mathrm{~m}$ spans with stay-in-place concrete decking. The length between the two abutments is around $90 \mathrm{~m}$ and the width of the bridge is around 26m (Liu et al., 2010b).

For the load test, two heavy trucks were used and placed at designed locations on the bridge. The weight of Truck A was $25,237 \mathrm{~kg}$ and the weight of Truck B was $24,865 \mathrm{~kg}$. The distance between the center of the front axle and the center of the rear axle is $6.2 \mathrm{~m}$ and the distance between the outer edges of the each pair of rear axles is $2.5 \mathrm{~m}$. Three loading cases have been carried out as displayed in Figure 9(b). Since I-77 is a heavy traffic route, traffic control for strain gage placement is not allowed. The physical constraints inspired the use of 3D LiDAR scanner for static load deflection measurement (Figure 9(c)). Figure 9(d) shows the deflection measurements for position 1 where deflection below truckload is clearly shown. 


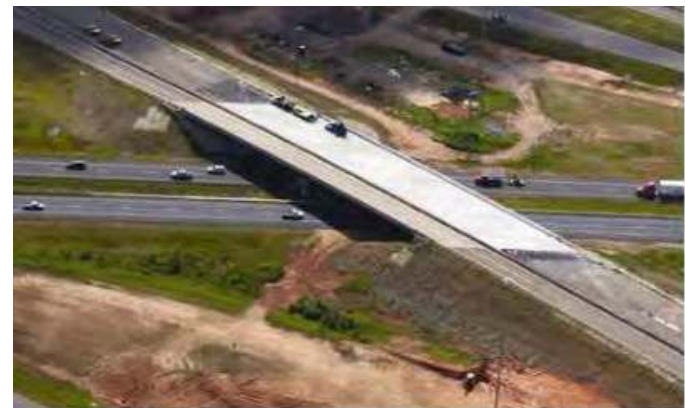

a) Langtree Road Bridge (I-77)

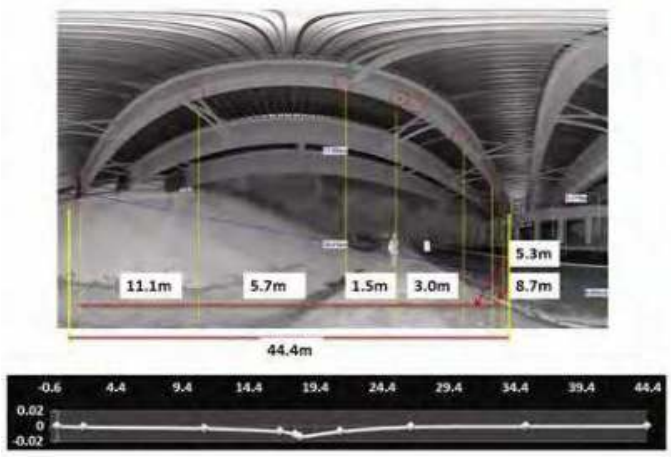

c) LiDAR Scan

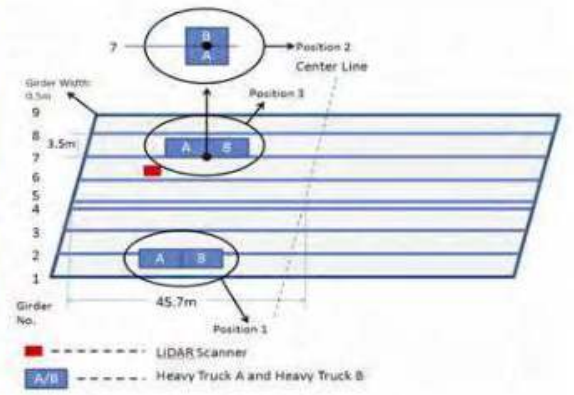

b) Truck Load Positions

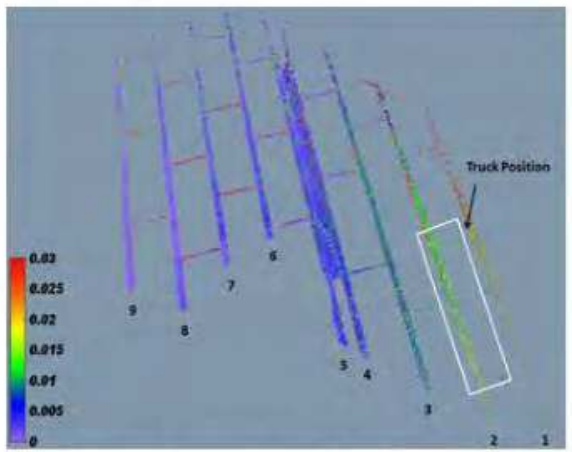

d) Displacement Field (Position 1)

Fig. 9. Langtree Road Bridge over I-77 Highway: a) Bridge under Load Test; b) Load Truck Positions; c) LiDAR Scan with Clearance Measurements; d) Deflection Values under Each Girder (Liu et al. 2011b)

\section{Examples of SLV applications for bridge monitoring}

To determine vibration-related problems or inverse engineer the vibration measurements to determine damage within a bridge, the natural modal behaviors of the bridge must first be studied. Typically, contact transducers such as accelerometers or geophones are used in the vibration study of bridges. However, because of the sizes of a bridge, large grids of sensor placements typically resulted in long cables in place and result in extensive time and efforts for test preparation. SLV would have solved such problems. The following describes the modal testing on a military bridge.

\subsection{SLV for full-scale bridge vibration mode identification}

The Armored Vehicle Launched Bridges (AVLBs) are mobile military bridges used for tank crossing during military operations. Designed for Military Load Capacity (MLC) of 60 to 70 tons, these bridges are unique due to their structural complexity and to being light-weight. Constructed of high-strength aluminum alloy and steel, AVLBs are scissor-type structures usually built with two treadways supported on four hinged girders with tapered 
approaches. The bridge is typically mounted on a launcher and has a hydraulic mechanism to open the bridge. The average AVLB weight is approximately 13 tons with a span of 18.3 $\mathrm{m}$. Figure 10 shows a typical AVLB bridge (10a) and the close up of the center hinge for mechanical opening (Chen et al., 2002).

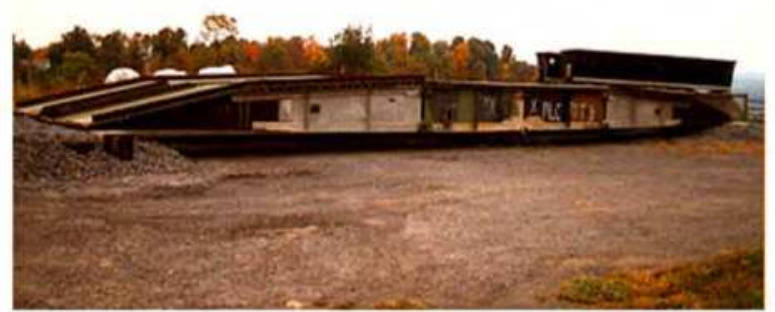

a) Armored Vehicle Launched Bridge

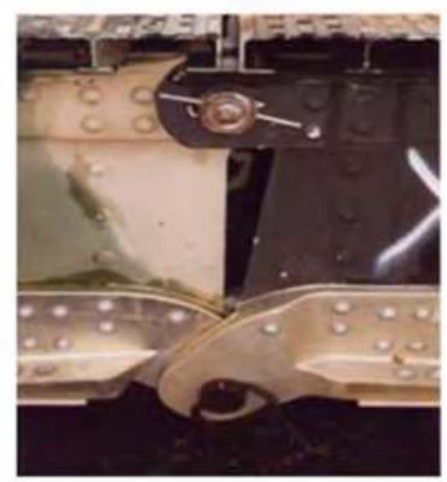

b) Details of Center Hinge

Fig. 10. AVLB: a) Entire Bridge View and b) Close Up of Center Hinge [34] (Chen et al. 2002)

AVLBs are designed to resist cycles of launching impact and heavy tank loads, hence dynamic impact dominates the design limit states. As a result, the most common damages found on the AVLBs are cracking from high-stress, low-fatigue cycle loads (Cho, 1994). An understanding of the dynamic behaviors of the AVLB is therefore critical to the design and analysis of the bridge.

To simulate free-free conditions, the AVLB was suspended by four airbags underneath the four girders. Figure 11 shows the experimental setup which includes: a) an airbag underneath each of the girders and b) mechanical shakers. The airbags were used to separate the rigid body modes from the flexible modes and to minimize the effect of the supports on the bridge dynamic characteristics. Since the structure is hinged, to ensure uniform excitation, two shakers were placed symmetrically underneath each inner girder. The shakers were synchronized to provide the same amount of stroke at the same time.

The vibration data were measured using an Ometron VP4000 SLV which uses a "lock-in" approach for single frequency scans. To scan the AVLB, a crane was used to lift the laser to $18 \mathrm{~m}$ above the bridge (Figure 12). However, even at such height, it is difficult to collect the complete modal information. Figure 12(c) shows the stitched mode shape of the AVLB at 9 $\mathrm{Hz}$ excitation. To scan the entire AVLB with an allowable scan angle of 20 degrees would mean that the laser has to be at $64 \mathrm{~m}$ height.

Since the four girders act as loosely connected members, several torsion and out-of-phase bending modes have been observed. Figure 13 shows the first three bending modes of the AVLB (Nessler \& Lovelace, 1997). The results indicated that the AVLB behaves like a loosely coupled structure where the two treadways act independently. 


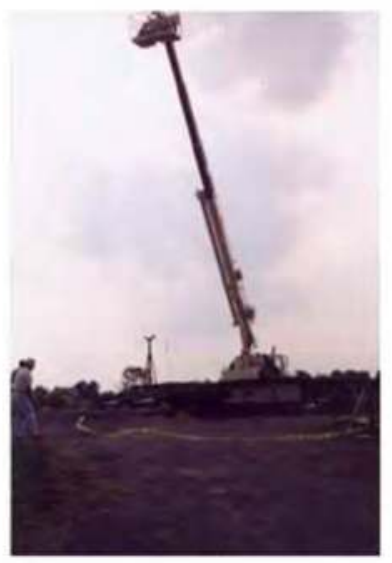

Damaged Mode 3 (31.5 Hz, free-free)

a) AVLB Scan with SLV on a Crane

b) Damage Mode Showing Pin-Removal

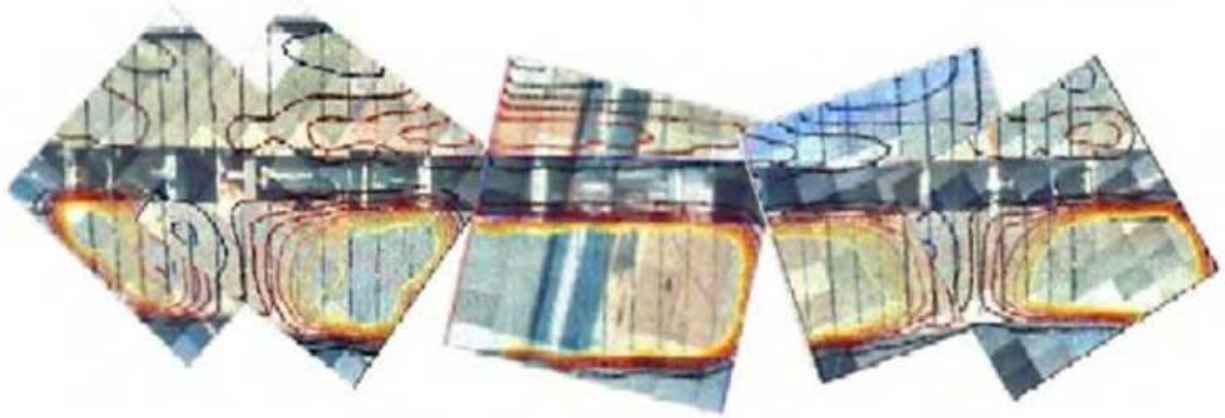

c) Stitched Mode Shapes at $9 \mathrm{~Hz}$ Excitation

Fig. 11. SLV Scan of AVLB Bridge

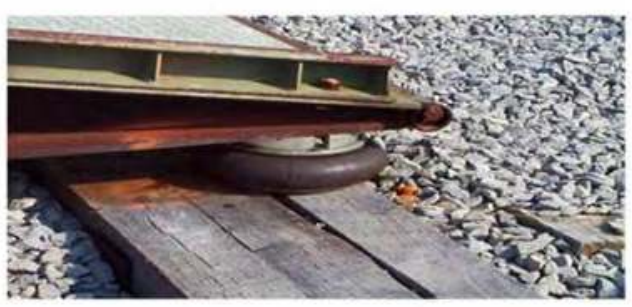

a) Airbag Support

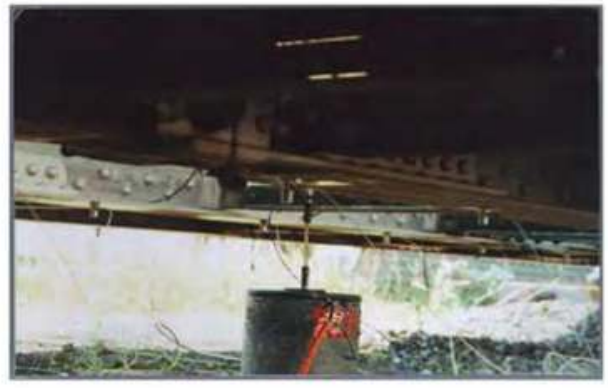

b) Shaker

Fig. 12. Testing Setup: a) Airbag and b) Shaker 


\section{Center Hinge}

a) AVLB

b) Mode 1

$(8.83 \mathrm{~Hz})$

c) Mode 2

$(18.9 \mathrm{~Hz})$

d) Mode 3

$(36.9 \mathrm{~Hz})$

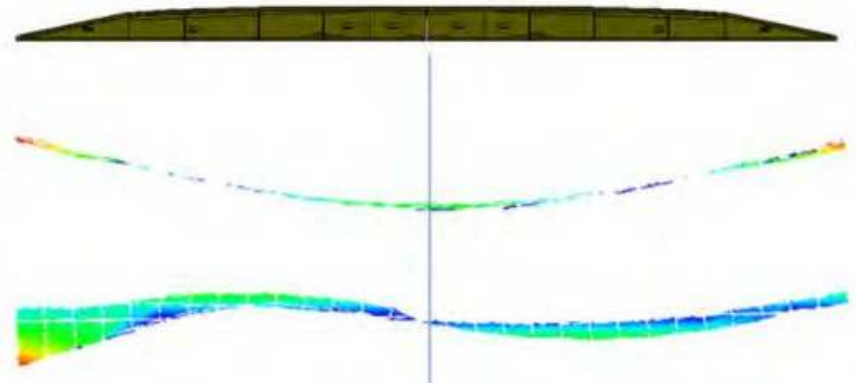

Fig. 13. Modal Behaviors of AVLB: a) AVLB; b) Mode 1; c) Mode 2; d) Mode 3

\subsection{SLV for damage detection on bridges}

Crack detection using vibration method has been investigated as early as early 1900s (DiPaquale et al. 1990, Hearn \& Testa, 1991, Hausner et al. 1997,). Using multiple axial mode frequencies, Adams et al. (1978) were able to identify damage location on a straight bar. Cawley and Adams (1979) presented a method using the ratio of frequency changes in two modes obtained both experimentally and numerically to locate damage. To accommodate SLV vibration scans, a damage detection algorithm based on the strain energy distribution (SED) approach is presented (Pandey et al., 1991, Park \& Stubbs, 1995). One of the key features of the strain energy distribution approach is that it is readily implementable to SLV for non-contact damage detection.

The SED method is based on changes in curvature of the mode shapes of a vibrating structure. Theoretical computation of SE is determined by taking the double integration of the derivatives of the measured mode shapes as follows

$$
\left[U_{i, a b c d}(x, y)\right]=\frac{D}{2} \int_{a}^{b d} \int_{c}^{d}\left\{\begin{array}{l}
{\left[\psi_{i, x}^{\prime \prime}(x, y)\right]^{2}+\left[\psi_{i, y}^{\prime \prime}(x, y)\right]^{2}+2 v\left[\psi_{i, x}^{\prime \prime}(x, y)\right]\left[\psi_{i, y}^{\prime \prime}(x, y)\right]} \\
+2(1-v)\left[\psi_{i, x y}^{\prime \prime}(x, y)\right]^{2}
\end{array}\right\} d x d y
$$

where $D$ is flexural rigidity and $\psi(x, y)$, is the mode shape function or modal operational shape function and can be determined using modal testing with the scanning laser which generates the mode shape in $\mathrm{x}$ and $\mathrm{y}$ directions.

Using SLV, the measurements can be either frequency response functions at single frequency or operating deflection shapes at individual frequencies. The double primes $\left(\psi^{\prime \prime}(x)\right)$ in Equation (8) denote the second derivatives of the shape function. The SED takes its integration over small intervals, i.e. $(a-b)$ along the horizontal axis (i.e., $x$-axis) and $(c-d)$ along the vertical axis (i.e. $y$-axis), which is the distance between two sampling points. 
For damaged cases, it is assumed that the flexural rigidity does not change and the damaged strain energy can be expressed as

$$
\left[U_{i, a b c d_{d}}(x, y)\right]=\frac{D}{2} \int_{a}^{b} \int_{c}^{d}\left\{\begin{array}{l}
{\left[\psi_{i, x_{d}}^{\prime \prime}(x, y)\right]^{2}+\left[\psi_{i, y_{d}}^{\prime \prime}(x, y)\right]^{2}+2 v\left[\psi_{i, x_{d}}^{\prime \prime}(x, y)\right]\left[\psi_{i, y_{d}}^{\prime \prime}(x, y)\right]} \\
+2(1-v)\left[\psi_{i, x y_{d}}^{\prime \prime}(x, y)\right]^{2}
\end{array}\right\} d x d y
$$

where the lower level subscript, $d$, denotes the strain energy of the damaged structure.

Local stiffness reduction as a result of cracking or damage would then be reflected in a local increase of SE. This local SE increase is present in different deflected shapes. The SED is computed on a mode-by-mode and element-by-element basis. It has been shown that any local stiffness reduction would lead to a concentration of the local curvature near the damaged cross section, hence producing higher SE. As a result, a comparison of the SEDs for damaged and intact structures can reveal locations of defects. Realistically, SE computations should take into consideration the reduction of cross sections. However, since crack locations are generally unknown beforehand, it is assumed that the effect is much smaller than the element sizes considered and is hence ignored. To detect damage, the numerical difference between damaged and undamaged SED values is used (Chen et al., 2000)

$$
\Delta U_{i, a b c d}(x, y)=U_{i, a b c d}(x, y)-U_{i, a b c d_{d}}(x, y)
$$

Since SED is a function of curvature, its sensitivity improves with increased spatial data densities. Again, using SLV, the problem is easily addressed. Figure 12c shows damage detection on the AVLB by removing one of the hinges at the quarter point on the bridge.

\subsection{SLV for cable tension measurements}

To ensure the safety and integrity of tied arch bridges, it is crucial that tension levels in cables be monitored and do not exceed their design levels. One possible approach would be to correlate the vibration frequencies with the tensions in these cables. However, due to their long length, access to these cables for mounting contact sensors is not easy. Again using SLV, this problem can be solved.

Traditionally, cable vibration measurements of natural frequencies are used to predict cable tension using the taut string model, where the natural frequencies, $\omega_{n}$, for the out-of-plane motion of a suspended cable are given as (Leonard, 1988):

$$
\omega_{n}=n \pi \sqrt{\frac{T}{m L^{2}}}
$$

where $n=n^{\text {th }}$ mode of vibration, $m=$ distributed mass per unit length, $T=$ cable tension, and $L=$ total or effective length of the cable. If the vibration frequencies can be clearly identified, then tension level can be back-calculated with exact measurements of the three unknowns, $\omega_{\mathrm{n}}, m$ and $L$ :

$$
T=\left(\frac{\omega_{n}}{n \pi}\right)^{2} m L^{2}
$$


The distributed mass, $m$, usually does not alter significantly, unless the metal has been heavily corroded. $L$ is a function of the boundary condition, which typically was assumed to be pinned-pinned.

The approach is tested on the I-470 Bridge, which is also known as the Vietnam Veteran Memorial Bridge and is located in Wheeling, West Virginia (Chen \& Petro, 2005). The bridge has a total length over $457.2 \mathrm{~m}$ and a central span of $237.4 \mathrm{~m}$ long. The four-lane highway bridge spans across the Ohio River with eastbound traffic towards West Virginia, and westbound traffic towards Ohio. The arch or rib and the tie of the bridge are both box sections. The load on the bridge deck is transferred to the rib cage through 16 hangers with intervals at $13.7 \mathrm{~m}$ between the two piers on each side of the bridge. The cables are fabricated from class A zinc-coated steel structural strands. $203 \mathrm{~mm}$ PVC pipe has been used as protectors on the lower part of the cables. The nominal diameter of the cable is about 57.2 $\mathrm{mm}$. Each strand is pre-stretched under tension to about 155 tons. The modulus of elasticity of the braided cable is about $165.47 \times 10^{9} \mathrm{~N} / \mathrm{m}^{2}$. The strand has a minimum breaking strength of 310 tons. To prevent the cables from impacting each other, elastic spacers have been placed between the cables. The hanger acts as stress transmitter, for the box arch to carry the dead load of the bridge deck. The design tension levels in each cable were assumed not to exceed $10 \%$ of the cable's breaking strength (31 tons). Hence, this limit was used as a check on cable safety.

The testing was conducted with the SLV placed on the shoulder of the bridge deck (Figure 14). The vibration measurements were made under regular traffic conditions. The direct velocity data were collected at a sampling rate of $1 \mathrm{kHz}$ with 50,000 data points. Spectrum analysis is then conducted on the time domain signals. The environmental condition on the test date is sunny with mild breezes.

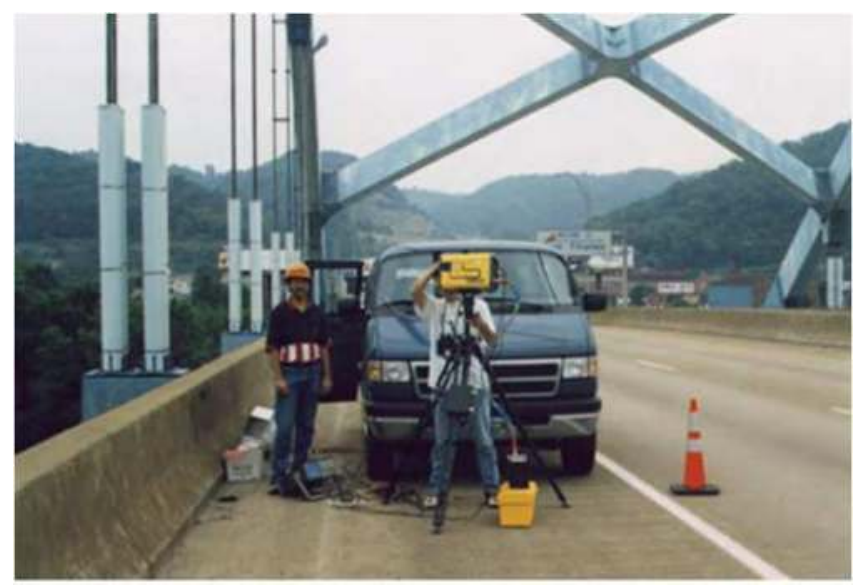

Fig. 14. Cable Vibration Measurements from the Bridge Deck [41] (Chen et al. 2005)

Figure 15 shows the basic structure of the I-470 Bridge with the measured vibration frequencies and estimated tension loads. The tension levels were determined using equation (11). If each strand carries the same load, the total tension in each hanger would be four times the tension level in the strands. 


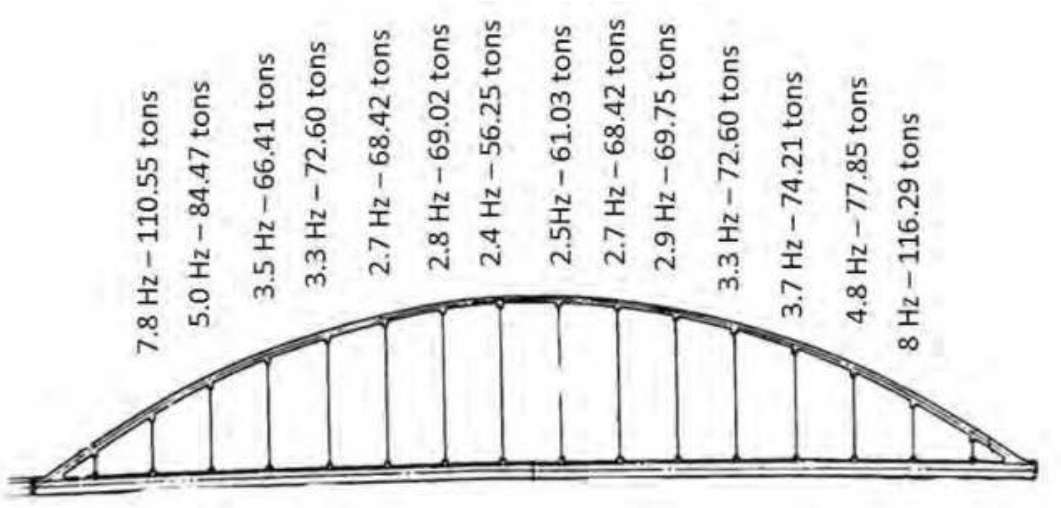

To Columbus, $\mathrm{OH}$

To Wheeling, WV

$237.4 \mathrm{~m}$

Fig. 15. Cable Load Capacity and Measured Vibration Frequencies (Chen et al. 2005)

\section{Discussion}

This chapter discusses several potential applications of scanning lasers for bridge monitoring. Other potential applications that are currently gaining popularity include high density, multi-dimensional geospatial model construction using LiDAR and photo imaging techniques for applications such as accident reporting and management, furniture (sign and luminaires) management, disaster mitigation and management, etc. Applying scanning laser technologies to bridge monitoring signifies a critical shift in bridge management paradigm it naturally integrates conventional visual inspection and paper reporting with digital computing via geoscience technologies such as Geological Information Systems (GIS) and advanced image analysis.

However, before the industry catch on with the technology, there is a need to carefully evaluate the potential impacts to the industry, in particular, in the form of life cycle cost analysis. Because of the capability in providing high resolution spatial information from a distance away, commercializing scanning laser technologies poses different issues than those faced by other structural monitoring science and technologies including issues of privacy and security, issues about redundancy in image information and legality and technology relevancy issues related to commercialization. With this in mind, the technical barriers would be the issue of retrieving useful and legitimate CRS data from multi-variant imaging and data sources that can be best used in enhancing bridge infrastructure management. The potential of generating massive data in the order of petabytes also challenges the computing sciences and pushing the technology envelope towards unprecedented scale.

These are not easy issues to address, which have to be answered by all bridge managers, government and stakeholders. However, the societal benefits are tremendous: for example, there is the potential of conducting temporal effect studies. By temporal, we mean more 
frequent inspections/visits than current federally mandated two-year cycles, which would allow reliable imaging of the transformation of damage through time. With the digital, high resolution imaging techniques, it may also be possible to identify critical problems prior to disastrous failure, such as what happened to the Minnesota I-35 Bridge. It is also possible to report real time tracking of excessive truck loading and environmental loadings.

Finally, bridge management decisions are complex processes that must consider bridge conditions as well as bridge utility, available funding and impact of rehabilitation techniques. Bridge managers need a tool to enable "total management" decision-making. This consideration is critical to the development of RS technologies for structural health monitoring, since it helps us understand how remote sensing data is associated with the bridge utilities. However, such considerations also represent a need to revisit the definitions and operations of existing bridge management systems.

\section{Conclusion}

This chapter introduces two types of scanning laser technologies: 1) static range finding laser and 2) dynamic measurement laser. Several bridge monitoring applications of scanning laser technologies have been described including damage detection, underclearance measurements, load deflection measurements, post-event validations, damage detection, modal behavior identification and cable tension measurements. These examples of scanning laser application provide realistic scenarios for industry-wide implementation of scanning laser techniques for bridge monitoring and both technologies are ready to be commercialized. However, it is also pointed out that such applications can significantly influence conventional bridge inspection and management by forcing the integration of geoscience technologies and advanced image capture and processing techniques. However, much work needs to be done to ascertain critical issues such as data security, privacy and the management of massively generated data are first addressed.

\section{References}

Adams, R.D., Cawley, P., Pye, C.J. \& Stone, B.J. (1978). A Vibration Technique for Nondestructively Assessing the Integrity of Structures. Journal Mechanical Engineering Science, Vol. 20, No. 2, pp.93-100.

Aktan, A.E., Farhey, D.N., Helmicki, A.J., Brown, D.L., Hunt, V.J., Lee, K.L. \& Levi, A. (1997). Structural Identification for Condition Assessment: Experimental Arts. ASCE Journal of Structural Engineering, Vol. 123, No. 12, pp.1674-1685.

Al-Turk, E. \& Uddin, W. (1999). Infrastructure Inventory and Condition Assessment Using Airborne Laser Terrain Mapping and Digital Photography, Transportation Research Records, TRB, Vol. 1690, pp. 121-125.

Bian, H., Bai, L., Wang, X., Liu, W., Chen, S.E. \& Wang, S. (2011). Effective LiDAR Damage Detection: Comparing Two Detection Algorithms, Structural Engineers. Vo. 27, No. 137, pp.327-333. 
Boehler, W. and Marbs, A. (2002). 3D Scanning Instruments, Proceedings of CIPA, Heritage Documentation - International Workshop on Scanning for Cultural Heritage Recording, Corfu, Greece.

Cawley, P. and Adams, R.D. (1979). The Location of Defects in Structures from Measurements of Natural Frequencies, Journal of Strain Analysis, Vol. 14, No. 2, pp.49-57.

Charlotte City Council (2011). City of Charlotte Zoning Ordinance, City of Charlotte.

Chen, S.E. \& Petro, P. (2005). Nondestructive Bridge Cable Tension Assessment Using Laser Vibrometry, Experimental Techniques, Vol. 29, No. 2, pp. 29-32.

Chen, S.E., Rice, C., Boyle, C. \& Hauser, E. (2011). Small Format Aerial Photography for Highway Bridge Monitoring, ASCE Journal of Performance of Constructed Facilities, Vol. 25, No. 2, pp. 105-112.

Chen, S.E., Petro, S., Venkatappa, S., GangaRao, H. and Moody, J. (2002). Modal Testing of an AVLB Bridge, Experimental Techniques, Vol. 26, No. 6, pp.43-46.

Chen, S.E., Venkatappa, S., Petro, S.H. \& GangaRao, H. (2000). A Novel Damage Detection Technique Using Scanning Laser Vibrometry and A Strain Energy Distribution Method, Materials Evaluation, Vol. 58, No. 12, pp.1389-1394.

Cho, N. (1994). Preproduction Qualification Test (PPQT) of the Armored vehicle Launch Bridge (AVLB) - MLC 70 Upgrade Program, U.S. Army Tank-Automotive Command Final Report \# CSTA-7567.

Choi, S. \& Stubbs, N. (1997). Nondestructive Damage Detection Algorithm for 2-D Plates, Smart Systems for Bridges, Structures, and Highways, Proceeding of SPIE, Vol. 3043, pp.193-204.

Curless, B. \& Levoy, M. (1996). A Volumetric Method for Building Complex Models from Range Images, Proceedings of SIGGRAPH, pp.303-312.

DiPasquale, E., Ju, J.W., Atilla, A. \& Cakmak, A.S.(1990). Relation Between Global Damage Indices and Local Stiffness Degradation. ASCE Journal of Structural Engineering, Vol. 116, No. 5, pp.1440-1456.

Drain, L.E., The Laser Doppler Technique, Wiley-Interscience, Sussex, England, 1980.

Fritsch, D. \& Kilian, J.C. (1994). Filtering and Calibration of Laser-Scanner Measurements, Proceedings of ISPRS Commission III Symposium, SPIE, Vol. 2357, pp. 227-234.

Fuchs, P.A., Washer, G.A., Chase, S.B. \& Moore, M. (2004a). Application of laser-based instrumentation for highway bridges. ASCE Journal of Bridge Engineering, Vol. 9, No. 6., pp.541-549.

Fuchs, P.A., Washer, G.A., Chase, S.B. \& Moore, M. (2004b) Laser-based instrumentation for bridge load testing, ASCE Journal of Performance of Constructed Facilities. Vol. 18, No. 4, pp.213-219.

Girardeau-Montaut, D. \& Roux, M. (2005). Change detection on points cloud data acquired with a ground laser scanner. Proceedings of Workshop Laser scanning 2005, Enschede, the Netherlands.

Hausner, G.W., Bergman, L.A., Caughey, T.K., Chassiakos, A.G., Claus, R.O., Masri, S.F., Skelton, R.E., Soong, T.T., Spencer, B.F. \& Yao, J.T.P. (1997). Structural Control: Past, present, and Future, ASCE Journal of Engineering Mechanics, Vol. 123, No. 9, pp.897-958. 
Hearn, G. \& Testa, R.B. (1991). Modal Analysis for Damage Detection in Structures. ASCE Journal of Structural Engineering, Vol. 117, No. 10, pp.3042-3063.

Jelalian, A.V. Laser Radar Systems. Artech House, Boston, London, 1992.

Junge, B. (1994). Experiences with Scanning Laser Vibrometry in Automotive Industries, Proceedings of SPIE, Vol. 2358, pp.377-382.

Kim, Y.R., Hummer, J.E., Gabr, M., Johnston, D., Underwood, B.S., Findley, D.J. \& Cunningham, C.M. (2008). Asset Management Inventory and Data Collection, Final Report, FHWA/NC/2008-15.

Lefevre, R. J. (2000). Radar bridge clearance sensor. Proceedings of IEEE 2000 International Radar Conference, Alexandria, VA, pp. 660-665.

Leonard, J.W. (1988), Tension structures - behavior and analysis, McGraw-Hill, New York, NY.

Lichti, D.D. \& Gordon, S.J. (2004). Error propagation in directly georeferenced terrestrial laser scanner point clouds for cultural heritage recording, Proceedings of WSA2 Modeling and Visualization, Athens, Greece.

Liu, M., Frangopol, D.M. \& Kim, S. (2009). Bridge Safety Evaluation Based on Monitored Live Load Effects, ASCE Journal of Bridge Engineering, Vol. 14, No. 4, pp. 257-269.

Liu, W.Q., Chen, S.E. \& Hauser, E. (2010a). LiDAR-Based Bridge Structure Defect Detection, Experimental Techniques, DOI: 10.1111/j.1747-1567.2010.00644.x.

Liu, W.Q., Chen, S.E. \& Hauser, E. (2011). Bridge Clearance Evaluation Based on Terrestrial LiDAR Scan, ASCE Journal of Performance of Constructed Facilities, doi:10.1061/(ASCE)CF.1943-5509.0000208.

Liu, W.Q., Chen, S.E., Boyajian, D. \&Hauser, E. (2010b) Application of 3D LiDAR Scan of Bridge Under Static Load Testing, Materials Evaluation, Vol. 68, No.12, pp.13591367.

Nessler, G. \& Lovelace, D. (1997). Final Report on Acquisition of Frequency Response Data on an Armored Vehicle Launched Bridge (AVLB).

Oliver, D.E. (1995). Scanning Laser Vibrometer for Dynamic Deflection Shape Characterization of Aerospace Structures, Proceedings, SPIE, Vol. 2472, pp.12-22.

Pandey, A.K., Biswas, M. \& Samman, M.M. (1991). Damage Detection from Changes in Curvature Mode Shapes, Journal of Sound and Vibration, Vol. 145, No. 2, pp.321-332.

Park, S. \& Stubbs, N. (1995). Bridge Diagnostics via Vibration Monitoring, Proceedings of SPIE, Vol. 2719, pp. 36-45.

Pieraccini, M. \& Parrini, F. et al., (2007). Static and dynamic testing of bridges through microwave interferometry. NDTEE International, Vol. 40, pp. 208-214.

Rueger, J.M., Electronic Distance Measurements: An Introduction, Springer-Verlag, New York, 1990.

Shinozuka, M. \& Rejajaie, S.A. (2000). Analysis of Remotely Sensed Pre- and Post-Disaster Images for Damage Detection, Smart Structures and Materials, Proceedings of SPIE, Vol. 3988, pp. 307-318.

Smith, D.E., Zuber, M.T., Neumann, G.A. \& Lernoine, F.G. (1997). Topography of the Moon from the Clementine LiDAR, Journal of Geophysical Research,Vol.102, No. E1, pp. 1591-1611. 
Watson, C., Chen, S.E., Bian, H. \& Hauser, E. (2011). 3D Terrestrial LiDAR for Operational Bridge Clearance Measurements, ASCE Journal of Performance of Constructed Facilities, doi:10.1061/(ASCE)CF.1943-5509.0000277. 


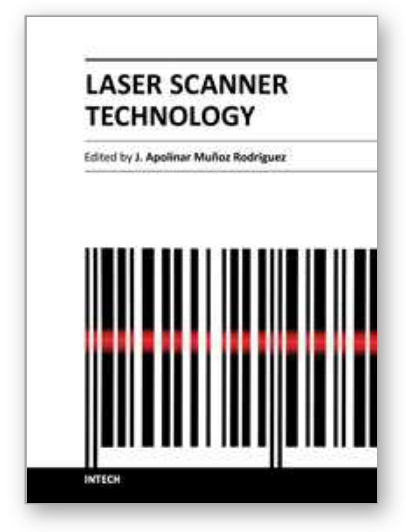

\author{
Laser Scanner Technology \\ Edited by Dr. J. Apolinar Munoz Rodriguez
}

ISBN 978-953-51-0280-9

Hard cover, 258 pages

Publisher InTech

Published online 28, March, 2012

Published in print edition March, 2012

Laser scanning technology plays an important role in the science and engineering arena. The aim of the scanning is usually to create a digital version of the object surface. Multiple scanning is sometimes performed via multiple cameras to obtain all slides of the scene under study. Usually, optical tests are used to elucidate the power of laser scanning technology in the modern industry and in the research laboratories. This book describes the recent contributions reported by laser scanning technology in different areas around the world. The main topics of laser scanning described in this volume include full body scanning, traffic management, 3D survey process, bridge monitoring, tracking of scanning, human sensing, three-dimensional modelling, glacier monitoring and digitizing heritage monuments.

\title{
How to reference
}

In order to correctly reference this scholarly work, feel free to copy and paste the following:

Shen-En Chen (2012). Laser Scanning Technology for Bridge Monitoring, Laser Scanner Technology, Dr. J. Apolinar Munoz Rodriguez (Ed.), ISBN: 978-953-51-0280-9, InTech, Available from:

http://www.intechopen.com/books/laser-scanner-technology/laser-scanner-technology-for-bridge-monitoring

\section{INTECH}

open science | open minds

\section{InTech Europe}

University Campus STeP Ri

Slavka Krautzeka 83/A

51000 Rijeka, Croatia

Phone: +385 (51) 770447

Fax: +385 (51) 686166

www.intechopen.com

\section{InTech China}

Unit 405, Office Block, Hotel Equatorial Shanghai

No.65, Yan An Road (West), Shanghai, 200040, China

中国上海市延安西路65号上海国际贵都大饭店办公楼 405 单元

Phone: $+86-21-62489820$

Fax: +86-21-62489821 
(C) 2012 The Author(s). Licensee IntechOpen. This is an open access article distributed under the terms of the Creative Commons Attribution 3.0 License, which permits unrestricted use, distribution, and reproduction in any medium, provided the original work is properly cited. 